\title{
The decline in digestive efficiency of US dairy cows from 1970 to 2014
}

\author{
S. B. Potts, M. Shaughness, and R. A. Erdman ${ }^{1}$ \\ Department of Animal and Avian Sciences, University of Maryland, College Park 20742
}

\begin{abstract}
Since the year 1970, US milk production per cow has more than doubled, in part because of large increases in feed intake. It is well established that increasing feed intake reduces diet digestibility in dairy cattle. Our objective was to determine whether the digestive efficiency of US dairy cows had also changed. We assembled a data set consisting of diet digestibility measured either by total collection of feces or by use of indigestible neutral detergent fiber (NDF) in lactating dairy cow studies published in the Journal of Dairy Science from July 1970 to July 2014. The data set contained 575 treatment means from 154 individual research trials conducted at 26 US institutions. Based on regression analysis, mean milk yield and dry matter intake (DMI) between 1970 and 2014 increased by 19.7 and $10.3 \mathrm{~kg} / \mathrm{d}$, respectively. Temporal effects on digestibility [dry matter (DM), crude protein $(\mathrm{CP})$, and $\mathrm{NDF}$ ] were determined using the regression model $Y_{i}$ $=\mathrm{YEAR}_{1970 i}+\mathrm{CP}_{i}+\mathrm{NDF}_{i}+e_{i}$, where $\mathrm{YEAR}_{1970 i}$ is the publication year minus $1970, \mathrm{CP}_{i}$ and $\mathrm{NDF}_{i}$ are diet constituents (\% of diet DM) that were included to account for their known effects on digestibility, and $e_{i}$ is the residual error. Dry matter digestibility decreased 0.07 percentage units/yr for a total reduction of 3.08 percentage units since 1970. Furthermore, CP and NDF digestibilities decreased 0.04 and 0.17 percentage units/ yr, respectively. To account for the potential effect of feed intake on digestibility, DMI as a percentage of body weight was added to the regression model. With DMI as a percentage of body weight in the model, temporal changes in DM, CP, and NDF digestibilities were no longer significant. This suggested that the apparent decline in DM digestibility could be mostly accounted for by simultaneous increases in level of feed intake. Despite lower apparent digestive efficiency, the modern dairy cow has greater production efficiency than the 1970s dairy cow because she produces more milk per unit of feed consumed and digested.
\end{abstract}

Received January 25, 2017.

Accepted March 6, 2017.

${ }^{1}$ Corresponding author: erdman@umd.edu
Key words: digestibility, digestive efficiency, dairy cow

\section{INTRODUCTION}

Between 1976 and 2016, milk production per cow more than doubled in the United States (NASS, 2016). These tremendous changes in production have been achieved through a combination of genetic selection for milk yield and improvements in nutrition and management that have facilitated the ability of cows to approach their production potential. Because feed intake is largely driven by energy demands (NRC, 2001), feed intake per cow also increased during this time. The development of ration formulation strategies that minimize potential negative effects of gut fill on feed intake have likely also promoted increases in feed intake. It is well established that high levels of feed intake depress diet digestibility (Tyrrell and Moe, 1975). Thus, it seems reasonable that the increase in intake, as a consequence of greater production and more refined ration formulation, might have resulted in a reduction of the efficiency with which gross energy is converted to digested energy, thereby reducing the amount of energy a cow can extract per unit of feed consumed.

Recently, attention has been given to improving feed efficiency in dairy cattle (Connor et al., 2013; Macdonald et al., 2014; VandeHaar et al., 2016). Digestive efficiency, or the efficiency by which gross energy is converted to digested energy, is an important component of biological efficiency and is a function of both an individual animal's ability to digest feed and the relative digestibility of the diet itself. It is important to consider whether intense selection for production over the last 4 decades has resulted in changes in the ability of dairy cows to digest feed, which could have implications for improving the cow's biological efficiency in the future. We hypothesized that digestive efficiency had decreased during the last 4 decades and that most of this reduction could be accounted for by concurrent increases in feed intake. The objective of this study was to determine whether changes in digestive efficiency occurred between 1970 and 2014 and, if changes occurred, whether these changes were associated with increases in feed intake. 


\section{MATERIALS AND METHODS}

\section{Database Derivation}

Literature Search. We constructed a database of peer-reviewed published data to examine temporal effects on the digestibility of DM, CP, and NDF between 1970 and 2014. Journal articles that included "digest" in the title or abstract that were published between July 1970 and July 2014 were included in the initial search. We only used studies published in Journal of Dairy Science because we were interested in examining temporal effects on the digestive efficiency of lactating dairy cattle; including other journals would have given results from other species that were not the focus of the analysis.

Data Inclusion and Collection. A total of 1,960 full-length articles resulted from the initial literature search, and only papers that detailed original research were considered for analysis. Publications were retained for analysis if (1) total-tract digestibility was determined in lactating dairy cows; (2) digestibility was measured either by total collection (TC) of feces or by use of indigestible NDF (iNDF) as an internal marker; (3) treatment DMI was reported; and (4) apparent totaltract digestibility of DM, CP, NDF, or any combination of those 3 was reported. Because we were interested in investigating digestibility changes over time for the US dairy cattle population, only studies conducted at institutions in the United States were included in the final data set.

When available, the following information was obtained from each publication: year of publication; study design; breed of cow studied; number of treatments; number of observations; length of collection period; standard error of the mean for digestibility (DM, CP, or NDF); percentage $\mathrm{CP}, \mathrm{NDF}$, starch, NFC, and forage in the diet; milk yield; milk fat concentration; and BW. The number of years between publication year and the year 1970 was calculated as the year of publication minus 1970 (YEAR $\left.{ }_{1970}\right)$. When both milk yield and fat concentration were reported, $4 \% \mathrm{FCM}$ was calculated as FCM $=0.4 \times$ milk yield $+15 \times($ milk fat concentration/100) $\times$ milk yield (NRC, 2001). If BW was reported, DMI as a percentage of $\mathrm{BW}\left(\mathbf{D M I}_{\mathrm{BW}}\right)$ was also calculated.

\section{Statistical Analysis}

Observations for apparent total-tract digestibility of DM, CP, and NDF were weighted as number of observations per standard deviation ${ }^{2}$, or the reciprocal of the squared standard error of the mean, according to Firkins et al. (1998) and St-Pierre (2001). If the standard error of the mean or standard deviation were not reported for digestibility (DM, CP, or NDF), observations could not be weighted and therefore were not included in the final analysis. Weights were standardized to a scale of 1 to maintain a weighted mean value that was on a scale similar to that of the response variable by dividing the weight factor for an individual treatment mean by the mean of all weight factors in the data set (St-Pierre, 2001).

To determine temporal effects on digestibility, data were analyzed using the GLM procedure of SAS (version 9.3; SAS Institute, Cary, NC) according to the model

$$
Y_{i}=\mathrm{YEAR}_{1970 i}+\mathrm{NDF}_{i}+\mathrm{CP}_{i}+e_{i}
$$

where $Y_{i}$ is apparent total-tract digestibility (\%), YEAR $_{1970 i}$ is the year of publication minus 1970, $\mathrm{NDF}_{i}$ and $\mathrm{CP}_{i}$ are the NDF and $\mathrm{CP}$ concentrations of the $\operatorname{diet}(\%$ of $\mathrm{DM})$, and $e_{i}$ is the residual error. Dietary constituents were included in the model to account for diet composition effects on digestibility. The WEIGHT statement was used to weight individual means as described earlier. To account for possible effects of feed intake on digestibility, $\mathrm{DMI}_{\mathrm{BW}}$ was included as a covariate in a second linear model:

$$
Y_{i}=\mathrm{YEAR}_{1970 i}+\mathrm{NDF}_{i}+\mathrm{CP}_{i}+\mathrm{DMI}_{\mathrm{BW} i}+e_{i} \cdot[2]
$$

Study was not included in either statistical model because study effects would be confounded with time, which was our primary variable of interest. The presence of outliers was determined by visual inspection and Cook's distance obtained for each nutrient digestibility using both Models 1 and 2; single observations with a Cook's distance $>0.20$ for either model were removed from the analysis of digestibility for the affected nutrient only (DM, CP, or NDF). Collinearity of response and explanatory variables used in Models 1 and 2 for the digestibility of each nutrient was assessed using variance inflation factors and the condition indices generated by the collinearity diagnostics option (COLLINOINT) of the REG procedure of SAS. Condition indices or variance inflation factors $>5.0$ were considered to be indicative of multicollinearity. Additionally, the relationships among response and explanatory variables included in Models 1 and 2 were investigated using the CORR procedure of SAS. Temporal effects for other response variables (DMI, $\mathrm{BW}, \mathrm{DMI}_{\mathrm{BW}}$, and diet $\mathrm{CP}, \mathrm{NDF}$, NFC, and forage as a percentage of DM) were determined by regressing responses as a function of $\mathrm{YEAR}_{1970}$. Significance was declared at $P<0.05$, and tendencies were declared at $P<0.10$. 


\section{RESULTS}

\section{Database}

Simple statistics for response and explanatory variables used for the analysis are shown in Table 1. A detailed list of references used to generate the database is provided in the Supplemental Materials. The database contained information from 137 journal articles that detailed 154 individual studies carried out across 26 institutions in the United States (Supplemental Table S1; https://doi.org/10.3168/jds.2017-12641). A total of 575 treatment means were reported from studies that used 2,023 individual cows. Holsteins were used in $90 \%$ of studies; the remaining $10 \%$ of studies used Jersey, Guernsey, Ayrshire, Brown Swiss, or crossbreed cows. Overall, $94 \%$ of articles reported DM digestibility, $86 \%$ reported CP digestibility, and $68 \%$ reported NDF digestibility. Seventy-nine percent of the treatment means were obtained using the TC method, and the remaining $21 \%$ of studies used iNDF to determine digestibility. Based on criteria described for outlier detection, 1, 5, and 4 means were identified as outliers and removed before examining temporal effects on DM (Dado and Allen, 1996), CP (Adams et al., 1988; Belyea et al., 1989; Dado and Allen, 1996), and NDF (Colucci et al., 1982; Dado and Allen, 1996) digestibilities, respectively. Furthermore, 12 and 10 studies did not report the standard error of the mean or standard deviation for DM and CP digestibility observations, respectively, and thus could not be used in the final analysis.

Relationships among response and explanatory variables used in Models 1 and 2 are provided in Supplemental Table S2 (https://doi.org/10.3168/jds.201712641). Diet CP percentage correlated positively with $\mathrm{DMI}_{\mathrm{BW}}(\mathrm{r}=0.25 ; P<0.01)$ and digestibility of $\mathrm{DM}$, $\mathrm{CP}$, and NDF ( $\mathrm{r}=0.19,0.37$, and 0.17 , respectively; all $P<0.01$ ), whereas diet NDF percentage correlated positively with NDF digestibility $(\mathrm{r}=0.44 ; P<0.01)$ but negatively with $\mathrm{DMI}_{\mathrm{BW}}(\mathrm{r}=-0.43 ; P<0.01)$. Condition indices and variance inflation factors for collinearity diagnostics did not exceed 2.0 for either model

Table 1. Simple statistics for response and explanatory variables used in the analysis of digestibility between 1970 and $2014^{1}$

\begin{tabular}{lcccc}
\hline Variable & $\mathrm{n}$ & Mean & $\mathrm{SD}$ & Range \\
\hline DM digestibility, \% & 529 & 66.6 & 3.94 & $52.5-78.7$ \\
CP digestibility, \% & 476 & 65.3 & 5.79 & $37.0-80.8$ \\
NDF digestibility, \% & 366 & 47.8 & 8.31 & $23.7-73.3$ \\
Diet CP, \% of DM & 528 & 16.4 & 2.07 & $4.00-23.9$ \\
Diet NDF, \% of DM & 394 & 34.2 & 4.77 & $23.9-50.2$ \\
DMI, \% of BW & 452 & 3.45 & 0.52 & $1.80-4.85$ \\
\hline
\end{tabular}

${ }^{1}$ Data are from 154 individual experiments from 26 research institutions across the United States published between July 1970 and July 2014. for any nutrient digestibility. These results suggest the absence of multicollinearity.

\section{Temporal Effects on Apparent Total-Tract Digestibility}

Figure 1 shows unweighted raw means for apparent total-tract digestibility over time $\left(\mathrm{YEAR}_{1970}\right)$. Regression coefficients for YEAR Y $_{1970}$ were $-0.04(P<0.01 ; \mathrm{n}$ $=529),-0.05(P=0.01 ; \mathrm{n}=476)$, and $-0.25(P<$ $0.01 ; \mathrm{n}=366$ ) for DM, CP, and NDF digestibilities, respectively. Thus, DM, CP, and NDF digestibilities decreased by $1.8,2.2$, and 11 percentage units between 1970 and 2014.

Coefficients for the regression of apparent total-tract digestibility as a function of $\mathrm{YEAR}_{1970}$ and diet $\mathrm{CP}$ and NDF (Model 1) are listed in Table 2. Digestibility of DM decreased 0.07 percentage units/yr between 1970 and $2014(P<0.01)$ after adjustments were made for diet $\mathrm{CP}$ and NDF percentage for a total reduction of 3.08 percentage units. Each unit increase in diet CP was associated with a 0.56 percentage unit increase in DM digestibility $(P<0.01)$, but diet NDF was not significant. After accounting for diet composition, CP and NDF digestibilities decreased 0.05 and 0.17 percentage units/yr since $1970(P=0.04$ and $P<0.01)$, respectively. Each unit increase in diet $\mathrm{CP}$ was associated with a 1.41 percentage unit increase in $\mathrm{CP}$ digestibility $(P<0.01)$, but diet NDF was not significant $(P=0.4)$. In contrast, both diet $\mathrm{CP}$ and NDF were significantly associated with NDF digestibility, with NDF digestibility increasing 0.70 and 0.74 percentage units per each unit increase in diet $\mathrm{CP}$ and $\mathrm{NDF}$, respectively $(P$ $<0.01)$. In part, the increase in $\mathrm{CP}$ digestibility with increasing diet $\mathrm{CP}$ reflects the dilution of the metabolic fecal CP, which is a function of diet DMI. Figure 2 illustrates the temporal effects on nutrient digestibilities after adjusting for diet NDF and CP concentrations. Apparent total-tract digestibilities of DM, CP, and NDF decreased by $3.08,2.20$, and 7.48 percentage units between 1970 and 2014 after considering the potential effects of diet composition on digestibility.

Regression coefficients for the prediction of apparent total-tract digestibilities of $\mathrm{DM}, \mathrm{CP}$, and $\mathrm{NDF}$ based on $\mathrm{YEAR}_{1970}$, diet $\mathrm{CP}$ and NDF percentages, and $\mathrm{DMI}_{\mathrm{BW}}$ (Model 2) are listed in Table 3. After accounting for concurrent increases in DMI, represented by $\mathrm{DMI}_{\mathrm{BW}}$, temporal effects on $\mathrm{DM}$ digestibility were no longer significant (coefficient $=-0.04, P=0.14$ ). Thus, it appears that a significant proportion $(43 \%)$ of the 3.08-percentage-unit decrease in DM digestibility observed for Model 1 could be accounted for by changes in feed intake. Digestibility of DM increased by 0.72 percentage units per each unit increase in diet $\mathrm{CP}(P$ 
Table 2. Regression coefficients and statistics for the prediction of DM, CP, and NDF digestibilities using the number of years between publication and $1970\left(\mathrm{YEAR}_{1970}\right)$ and diet $\mathrm{CP}$ and $\mathrm{NDF}$ (\% of diet DM) as covariates (Model 1$)^{1}$

\begin{tabular}{lccc}
\hline Item & DM & CP & NDF \\
\hline Intercept & & & \\
Coefficient & 59.3 & 42.1 & 15.0 \\
SE & 3.01 & 3.50 & 6.12 \\
$P$-value & $<0.01$ & $<0.01$ & 0.01 \\
YEAR 1970 & & & \\
Coefficient & -0.07 & -0.05 & -0.17 \\
SE & 0.02 & 0.02 & 0.04 \\
$P$-value & $<0.01$ & 0.04 & $<0.01$ \\
Diet CP, \% DM & & & \\
Coefficient & 0.56 & 1.41 & 0.70 \\
SE & 0.11 & 0.14 & 0.24 \\
$P$-value & $<0.01$ & $<0.01$ & $<0.01$ \\
Diet NDF, \% of DM & & & \\
Coefficient & -0.01 & 0.05 & 0.74 \\
SE & 0.05 & 0.05 & 0.09 \\
$P$-value & 0.86 & 0.35 & $<0.01$ \\
n & 346 & 304 & 334 \\
$\mathrm{R}^{2}$ & 0.10 & 0.28 & 0.27 \\
Root mean squared error & 3.56 & 3.32 & 6.65 \\
\hline
\end{tabular}

${ }^{1}$ Data are from 154 individual experiments from 26 research institutions across the United States published between July 1970 and July 2014.

$<0.01)$ and decreased 1.85 units per each unit increase in $\mathrm{DMI}_{\mathrm{BW}}(P<0.01)$ but was not significantly affected by diet $\mathrm{NDF}(P=0.11)$. Similar to DM digestibility, temporal effects on $\mathrm{CP}$ and NDF digestibilities also became nonsignificant $(P=0.27$ and 0.14 , respectively) after accounting for changes in both diet composition and feed intake over the 44-yr period. For CP digestibility, each unit increase in diet $\mathrm{CP}$ was associated with a 1.51-unit increase, whereas each percentage unit increase in $\mathrm{DMI}_{\mathrm{BW}}$ was associated with a 3.25 -unit decrease (both $P<0.01$ ). Both diet $\mathrm{CP}$ and NDF were positively associated with NDF digestibility (0.97 and 0.70 , respectively; both $P<0.01$ ). Interestingly, NDF digestibility was not significantly affected by $\mathrm{DMI}_{\mathrm{BW}}$ $(P=0.45)$ in Model 2. Figure 3 illustrates changes in nutrient digestibilities after adjusting for the effects of diet composition and $\mathrm{DMI}_{\mathrm{BW}}$.

\section{Temporal Effects on Production and Diet Characteristics}

There was a significant quadratic effect of $\mathrm{YEAR}_{1970}$ on average daily DMI, with daily DMI increasing from 14.3 to $24.6 \mathrm{~kg} / \mathrm{d}$ over the $44-\mathrm{yr}$ period (Figure $4 \mathrm{~A}$ ). Thus, among the studies summarized, reported DMI increased by $72 \%$. Furthermore, feed intake as a percentage of BW increased by $42 \%$ over the 44 -yr period (Figure 4B; $P<0.01$ ). Between 1970 and 2014, average daily milk yield increased by $98.5 \%$ (from 20.0 to 39.7 $\mathrm{kg} / \mathrm{d}$; Figure 5A). Similar to milk yield, FCM yield in-
A

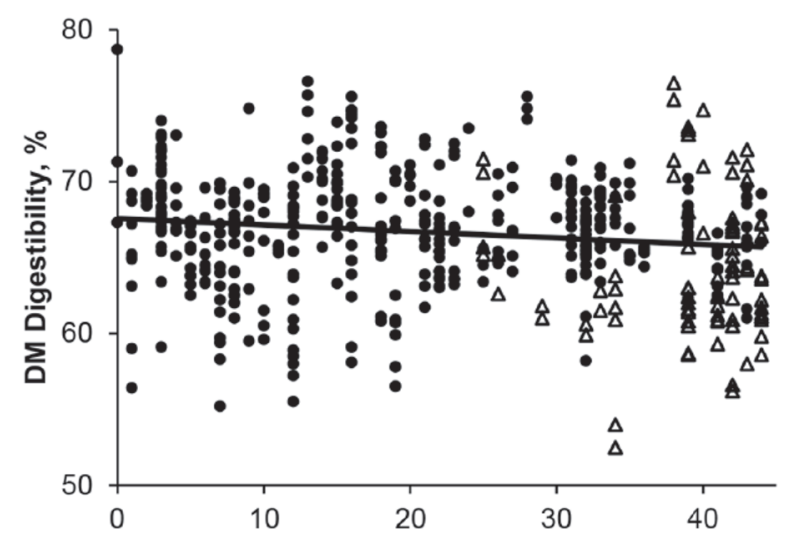

B

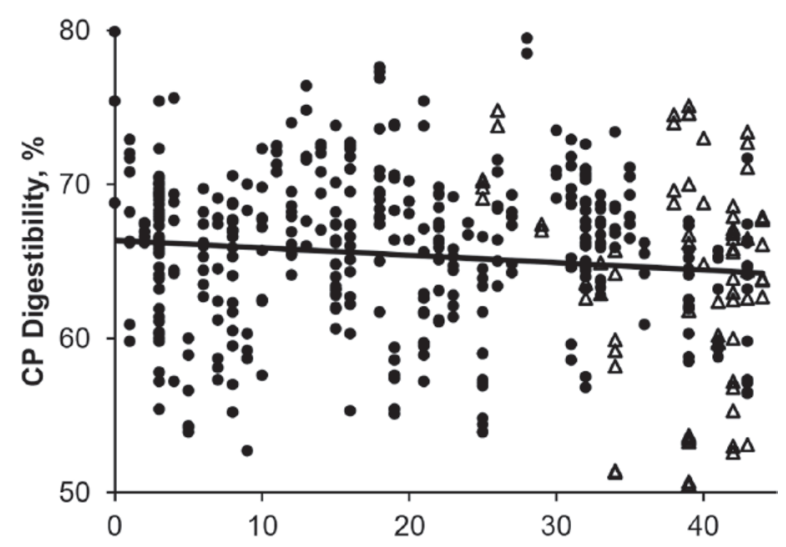

C

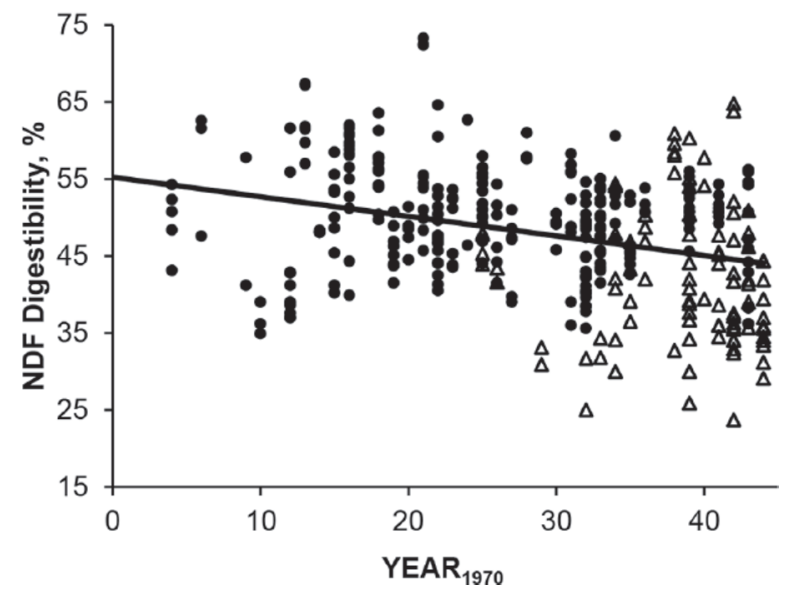

Figure 1. Relationship between publication year minus 1970 $\left(\mathrm{YEAR}_{1970}\right)$ and raw unweighted means for digestibilities of $(\mathrm{A}) \mathrm{DM}(\mathrm{y}$ $=-0.04 \mathrm{x}+67.6$; intercept $\mathrm{SE}=0.33$; intercept $P<0.01$; slope $\mathrm{SE}=$ 0.01 ; slope $\left.P<0.01 ; \mathrm{R}^{2}=0.02 ; \mathrm{RMSE}=3.90 ; \mathrm{n}=529\right)$, (B) $\mathrm{CP}(\mathrm{y}$ $=-0.05 \mathrm{x}+66.4 ;$ intercept $\mathrm{SE}=0.51 ;$ intercept $P<0.01 ;$ slope $\mathrm{SE}=$ 0.02 ; slope $P=0.01 ; \mathrm{R}^{2}=0.01 ; \mathrm{RMSE}=5.76 ; \mathrm{n}=476$ ), and (C) NDF $(\mathrm{y}=-0.25 \mathrm{x}+55.2$; intercept $\mathrm{SE}=1.25$; intercept $P<0.01 ;$ slope $\mathrm{SE}$ $=0.04 ;$ slope $\left.P<0.01 ; \mathrm{R}^{2}=0.10 ; \mathrm{RMSE}=7.89 ; \mathrm{n}=366\right)$. RMSE $=$ root mean squared error. Closed circles indicate digestibilities determined by total collection of feces, and open triangles represent digestibilities determined by indigestible NDF. 
A

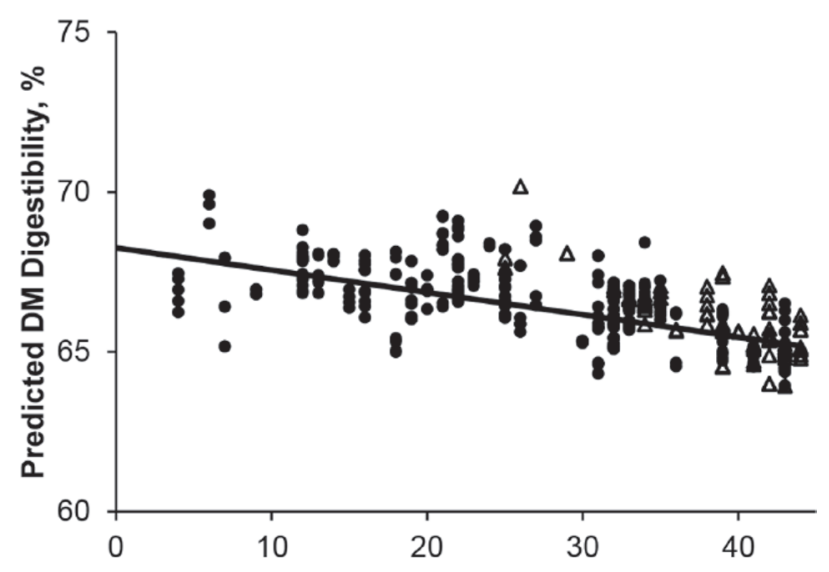

B

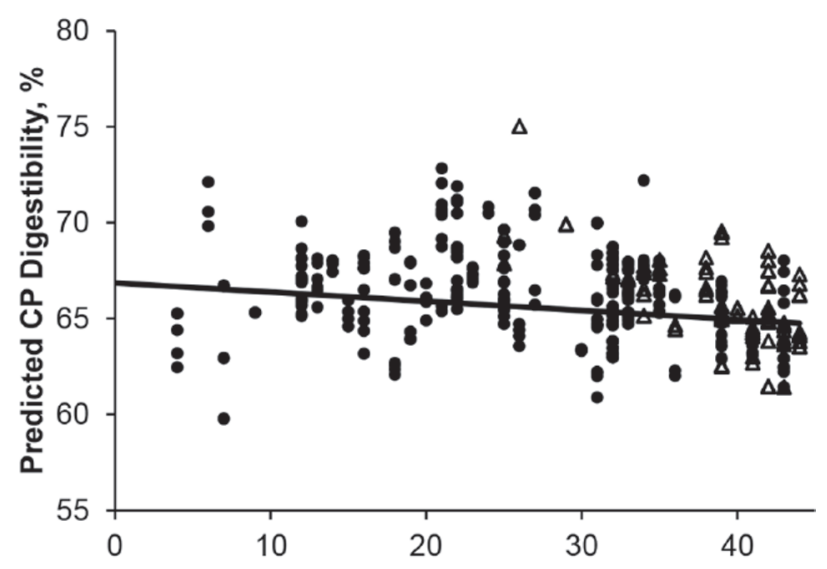

C

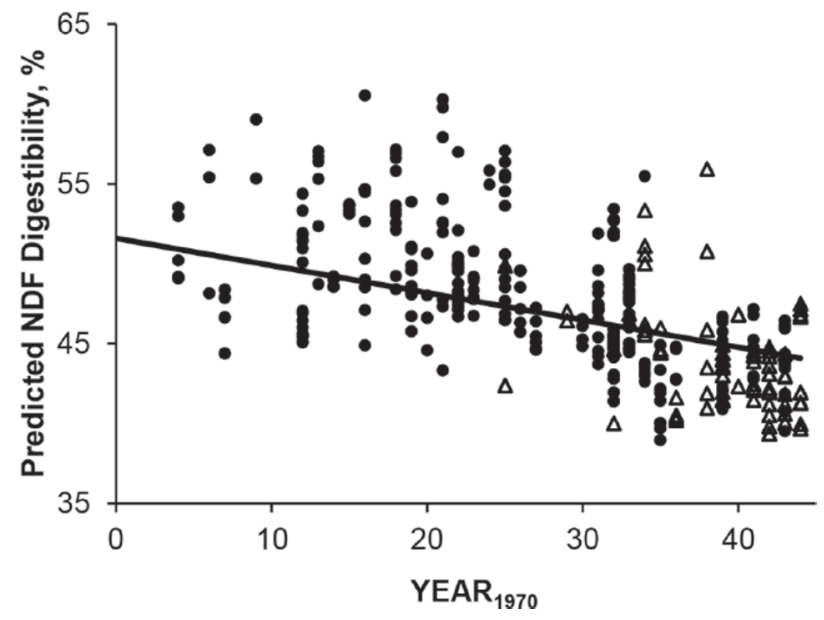

Figure 2. Relationship between publication year minus 1970 $\left(\mathrm{YEAR}_{1970}\right)$ and Model 1 predictions for digestibilities of $(\mathrm{A}) \mathrm{DM}(\mathrm{y}$ $=-0.07 \mathrm{x}+68.2),(\mathrm{B}) \mathrm{CP}(\mathrm{y}=-0.05 \mathrm{x}+66.9)$, and $(\mathrm{C}) \mathrm{NDF}(\mathrm{y}=$ $-0.17 \mathrm{x}+51.6)$ adjusted to the mean dietary NDF (mean $\pm \mathrm{SD} ; 34.2$ $\pm 4.8)$ and $\mathrm{CP}(16.4 \pm 2.1)$ concentrations for the data set. Closed circles indicate digestibilities determined by total collection of feces, and open triangles represent digestibilities determined by indigestible NDF. Statistics for the regression equations are shown in Table 2. creased $0.40 \mathrm{~kg} / \mathrm{d}$ per year since $1970(P<0.01$; data not shown). In the studies summarized, BW increased by $2.35 \mathrm{~kg} / \mathrm{yr}$ between 1970 and $2014(P<0.01)$; thus, mean BW has increased by $19 \%$ (from 543 to $647 \mathrm{~kg}$; Figure 5B). After accounting for putative breed differences, average BW still increased from 569 to $647 \mathrm{~kg}$ $(1.78 \mathrm{~kg} / \mathrm{yr})$, or $13.8 \%$, for Holstein cows $(P<0.01$; data not shown). Diet NDF content decreased from 37.6 to $32.4 \%$ between 1970 and 2014 (Figure 6A; $P$ $<0.01$ ), but temporal effects on dietary forage content were not significant (Figure 6B; $P=0.18$ ). Average diet $\mathrm{CP}$ content increased by 2.06 percentage units between 1970 and 2014 (Figure 6C; $P<0.01$ ), but diet starch content decreased by 11.1 percentage units (Figure 6D; $P<0.01)$.

\section{DISCUSSION}

In order for the results of this summary to be applied, it must be assumed that the reported temporal changes in cows used in the summarized experiments provide a representative sample that reflects the changes that have occurred in the US dairy cattle population in general. Daily milk production of cows for the summarized experiments increased from 20.0 to $39.7 \mathrm{~kg} / \mathrm{d}$, representing a 99\% increase between 1970 and 2014. During the same period, average annual milk production per

Table 3. Regression coefficients and statistics for the prediction of $\mathrm{DM}, \mathrm{CP}$, and NDF digestibilities using the number of years between publication and $1970\left(\mathrm{YEAR}_{1970}\right)$, diet CP and NDF (\% of diet DM), and DMI as a percentage of $\mathrm{BW}\left(\mathrm{DMI}_{\mathrm{BW}}\right)$ as covariates (Model 2$)^{1}$

\begin{tabular}{lccc}
\hline Item & DM & CP & NDF \\
\hline Intercept & & & \\
Coefficient & 65.1 & 55.0 & 12.8 \\
SE & 3.77 & 4.65 & 7.00 \\
$P$-value & $<0.01$ & $<0.01$ & 0.07 \\
YEAR $_{1970}$ & & & \\
Coefficient & -0.04 & -0.03 & -0.07 \\
SE & 0.02 & 0.03 & 0.05 \\
$P$-value & 0.14 & 0.27 & 0.14 \\
Diet CP, \% of DM & & & \\
Coefficient & 0.72 & 1.51 & 0.97 \\
SE & 0.12 & 0.15 & 0.25 \\
$P$-value & $<0.01$ & $<0.01$ & $<0.01$ \\
Diet NDF, \% of DM & & & \\
Coefficient & -0.09 & -0.05 & 0.70 \\
SE & 0.06 & 0.06 & 0.09 \\
$P$-value & 0.11 & 0.41 & $<0.01$ \\
DMI & & & \\
Coefficient & & -3.25 & -0.90 \\
SE & -1.85 & 0.73 & 1.20 \\
$P$-value & 0.59 & 0.45 \\
n & $<0.01$ & $<0.01$ & 296 \\
$\mathrm{R}^{2}$ & 304 & 271 & 0.27 \\
Root mean squared error & 0.16 & 0.34 & 6.14 \\
\hline
\end{tabular}

${ }^{1}$ Data are from 154 individual experiments from 26 research institutions across the United States published between July 1970 and July 2014. 
A

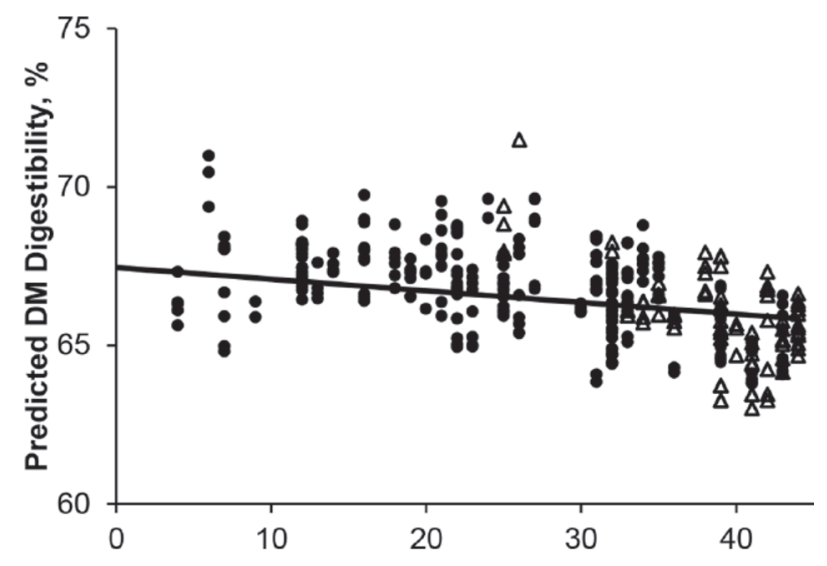

B

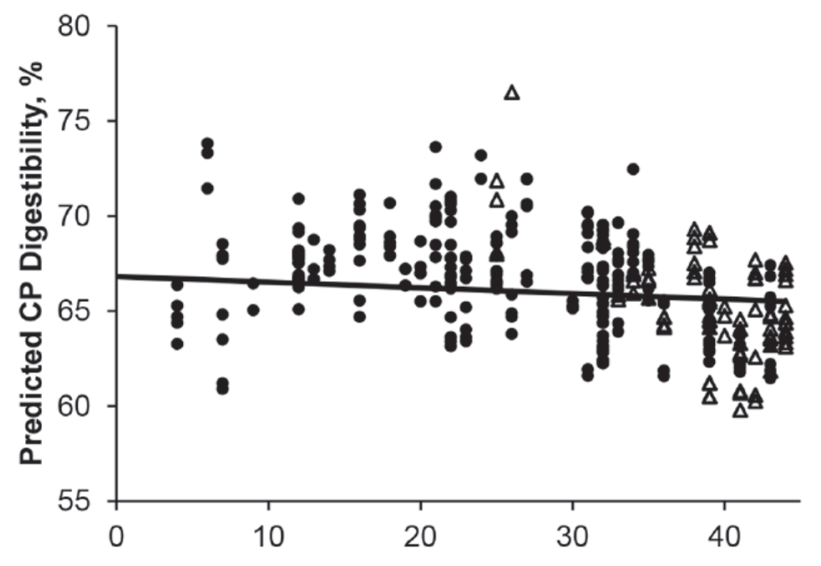

C

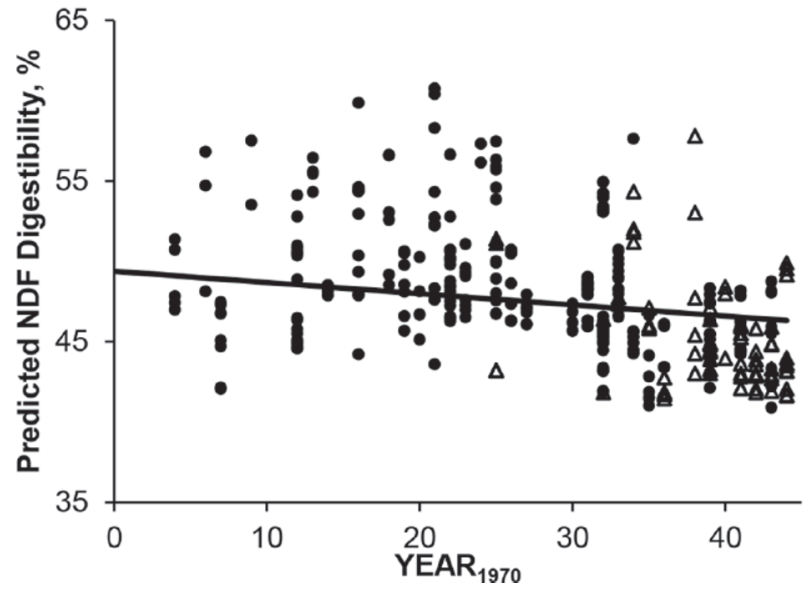

Figure 3. Relationship between publication year minus 1970 $\left(\right.$ YEAR $\left._{1970}\right)$ and Model 2 predictions for digestibilities of (A) DM (y $=-0.04 \mathrm{x}+67.5),(\mathrm{B}) \mathrm{CP}(\mathrm{y}=-0.03 \mathrm{x}+66.8)$, and (C) NDF $(\mathrm{y}=$ $-0.07 \mathrm{x}+49.4$ ) adjusted to the mean dietary NDF (mean \pm SD; 34.2 $\pm 4.8), \mathrm{CP}(16.4 \pm 2.1)$, and DMI as a percentage of BW (3.45 \pm 0.52 ) for the data set. Closed circles indicate digestibilities determined by total collection of feces, and open triangles represent digestibilities determined by indigestible NDF. Statistics for the regression equations are shown in Table 3. cow in the United States has increased from 4,432 to $10,118 \mathrm{~kg}$, representing a $128 \%$ increase (NASS, 2016). Reflecting the known relationship between milk production and feed intake (NRC, 2001), our results showed that daily DMI increased by $10.3 \mathrm{~kg}$ between 1970 and 2014. Assuming an average dietary $\mathrm{NE}_{\mathrm{L}}$ concentration of $1.55 \mathrm{Mcal} / \mathrm{kg}$ of diet DM (mature Holstein cow, 90 DIM; Table 14-7 in NRC, 2001), a 10.3-kg increase in daily DMI would provide an additional $16.0 \mathrm{Mcal} / \mathrm{d}$ of $\mathrm{NE}_{\mathrm{L}}$ (NRC, 2001). Using a milk $\mathrm{NE}_{\mathrm{L}}$ concentration of

A

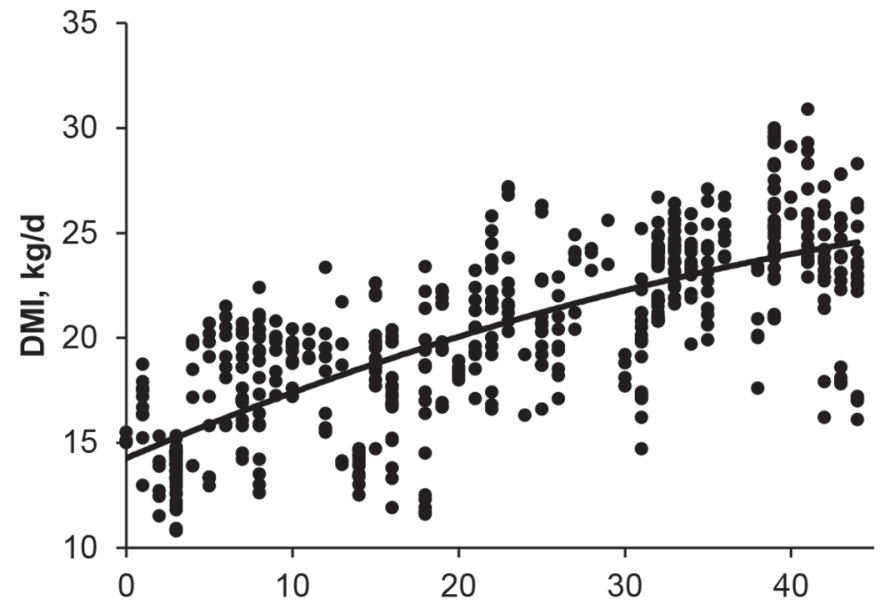

B

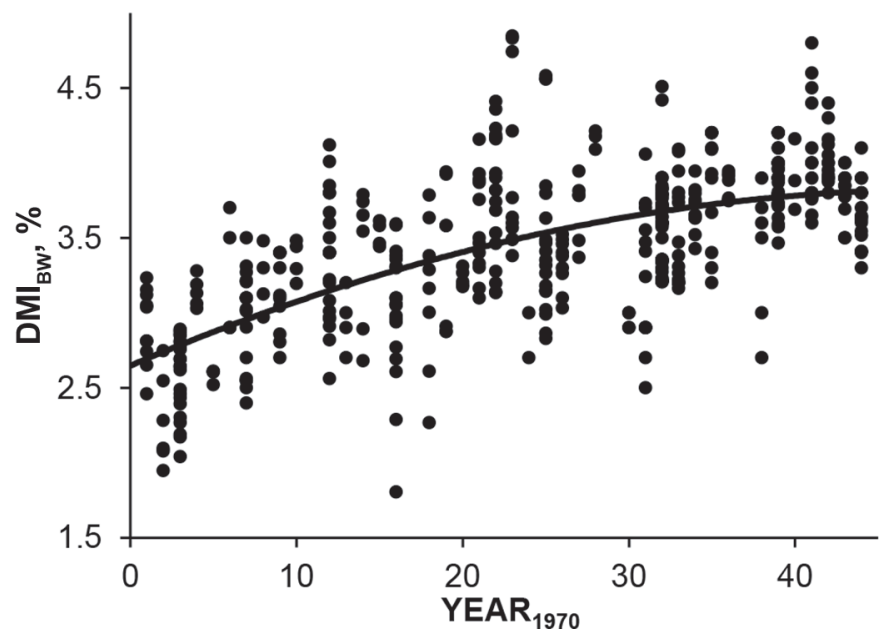

Figure 4. Relationship between publication year minus 1970 $\left(\mathrm{YEAR}_{1970}\right)$ and $(\mathrm{A}) \mathrm{DMI}\left(\mathrm{kg} / \mathrm{d}=-0.002 \mathrm{x}^{2}+0.34 \mathrm{x}+14.3\right.$; intercept $\mathrm{SE}=0.35$; intercept $P<0.01$; linear term $\mathrm{SE}=0.04$; linear term $P<$ 0.01 ; quadratic term $\mathrm{SE}<0.001$; quadratic term $P<0.01 ; \mathrm{R}^{2}=0.56$; $\mathrm{RMSE}=2.78 ; \mathrm{n}=562)$ and $(\mathrm{B}) \mathrm{DMI}$ as a percentage of $\mathrm{BW}\left(\mathrm{DMI}_{\mathrm{BW}}\right.$; $\%=-0.0005 \mathrm{x}^{2}+0.05 \mathrm{x}+2.65$; intercept SE $=0.06$; intercept $P<$ 0.01 ; linear term $\mathrm{SE}=0.006$; linear term $P<0.01$; quadratic term $\mathrm{SE}$ $<0.001 ;$ quadratic term $P<0.01 ; \mathrm{R}^{2}=0.43 ; \mathrm{RMSE}=0.39 ; \mathrm{n}=452$ ). $\mathrm{RMSE}=$ root mean squared error. 
$0.69 \mathrm{Mcal} / \mathrm{kg}$ (3.5\% fat, 3.0\% protein, and 5\% lactose; Equation 2-15 in NRC, 2001) and assuming an increase in maintenance requirements of $1.3 \mathrm{Mcal}$ of $\mathrm{NE}_{\mathrm{L}}$ due to the increase in $\mathrm{BW}$ since $1970\left(\mathrm{BW}^{0.75} \times 0.08 \mathrm{Mcal} / \mathrm{kg}\right.$; NRC, 2001), the increase in DMI would provide sufficient energy to produce $21.3 \mathrm{~kg} / \mathrm{d}$ more milk, which is close to the reported $19.7 \mathrm{~kg} / \mathrm{d}$ temporal change in milk production in our summary. Because of the similarities of the changes in milk production and the corresponding expected increases in DMI, we concluded that the reported changes in milk production and DMI for the cows used in these studies were reflective of the gen-

A

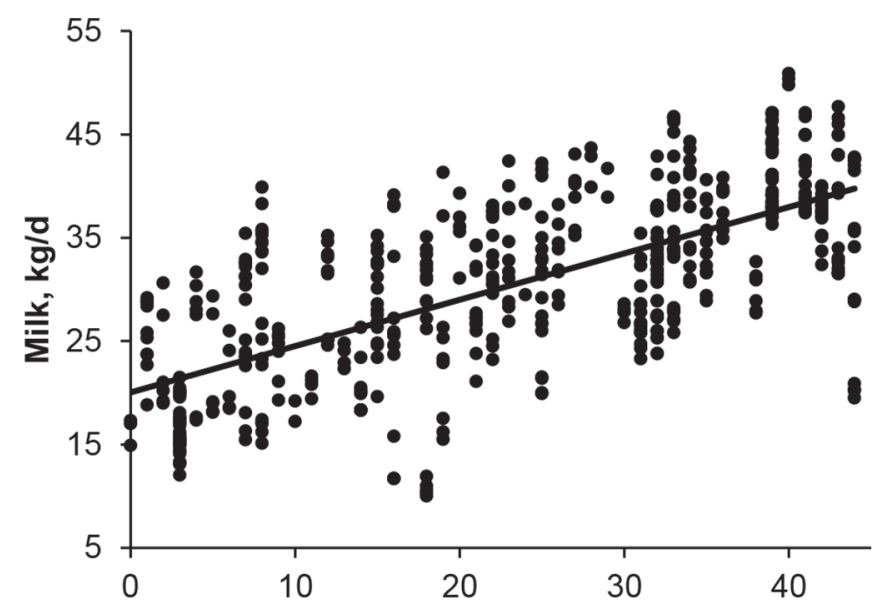

B

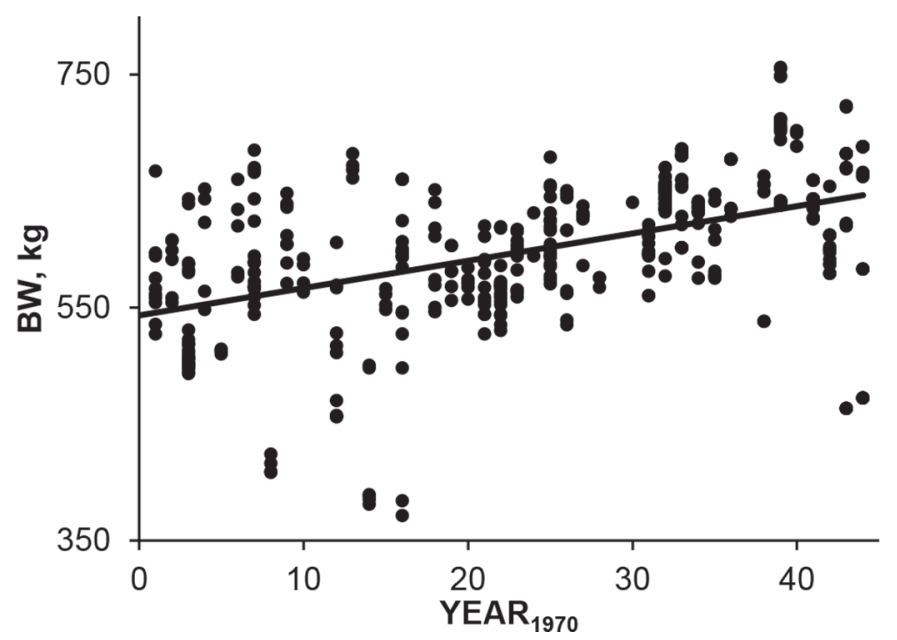

Figure 5. Relationship between publication year minus 1970 $\left(\mathrm{YEAR}_{1970}\right)$ and $(\mathrm{A})$ milk yield $(\mathrm{kg} / \mathrm{d}=0.45 \mathrm{x}+20.0$; intercept $\mathrm{SE}=$ 0.56 ; intercept $P<0.01$; slope $\mathrm{SE}=0.02$; slope $P<0.01 ; \mathrm{R}^{2}=0.47$; $\mathrm{RMSE}=6.39 ; \mathrm{n}=535)$ and $(\mathrm{B}) \mathrm{BW}(\mathrm{kg}=2.36 \mathrm{x}+543$; intercept SE $=5.81$; intercept $P<0.01 ;$ slope $\mathrm{SE}=0.20$; slope $P<0.01 ; \mathrm{R}^{2}=0.23$; RMSE $=56.1 ; \mathrm{n}=439)$. RMSE $=$ root mean squared error. eral changes that have occurred in the US dairy cattle population.

Our regression model predicted that mean BW increased by $103 \mathrm{~kg}$ (19\%) across the 44-yr period examined. Even after correcting for the effect of breed, noting that $10 \%$ of the studies included in our data set did not use $100 \%$ Holstein cows, the predicted increase in BW (78 kg) was still significant. To our knowledge, no reliable statistics on temporal changes in cow $\mathrm{BW}$ in the US dairy herd exist. In a reanalysis of USDABeltsville calorimetry data, Moraes et al. (2015) noted only small changes in mean BW of the Beltsville cows when grouped by decade beginning in 1963, and cows studied during the period 1984 to 1995 had the greatest BW. Hansen (2000) reported that Holstein cows selected for high milk yields between 1964 and 1999 had greater stature, rump width, and body depth than control cows that were not selected for high milk production. Although the exact magnitude of the change in BW in the US dairy cattle population is uncertain, the increase in BW between 1970 and 2014 found in this study was consistent with reports that Holstein dairy cows are getting taller (Bermingham et al., 2006; Beavers and Van Doormaal, 2016).

The method of measuring digestibility among different experiments (TC vs. iNDF) may have influenced our estimate of temporal effects on digestibility. Method of collection was not included in Models 1 and 2 for our analysis because it was confounded with time, which was our main variable of interest. Lippke et al. (1986) first reported on the use of the iNDF procedure in cattle and sheep. In our summary, the vast majority of studies $(26 / 29)$ utilizing iNDF were published after 2001. Visual inspection of individual data points in Figure 1 does not imply any methodology bias. However, there have been very few direct comparisons of TC and iNDF digestibility estimates in which both methods were used simultaneously. Lee and Hristov (2013) compared digestibility estimates using TC, iNDF, and acid insoluble ash as an internal marker. They observed that the iNDF marker method tended to overestimate DM digestibility for cows fed a low-protein diet but significantly underestimated digestibility for cows fed a high-protein diet. In general, acid insoluble ash tended to overestimate digestibility compared with TC and iNDF. Other studies have also shown that the accuracy of using iNDF as an internal maker to estimate total-tract digestibility is dependent on the type of diet (Cochran et al., 1986; Huhtanen et al., 1994). In the studies reported in our summary, the mean standard deviations for DM digestibility measured by TC and iNDF were 2.56 and 3.08 , respectively. This suggests that precision in measurement of digestibility by $\mathrm{TC}$ is greater than that using iNDF. However, by design of 
A

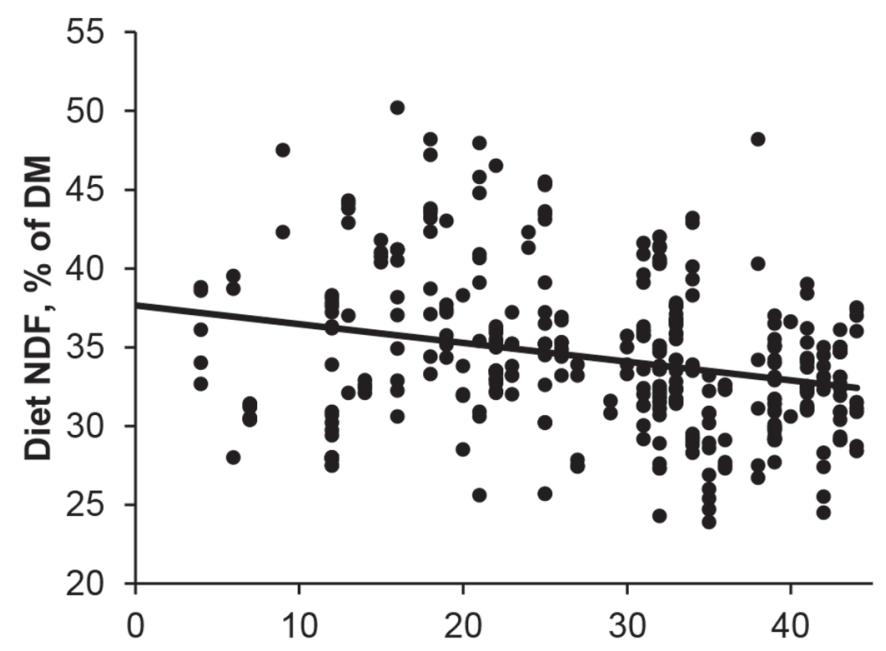

C

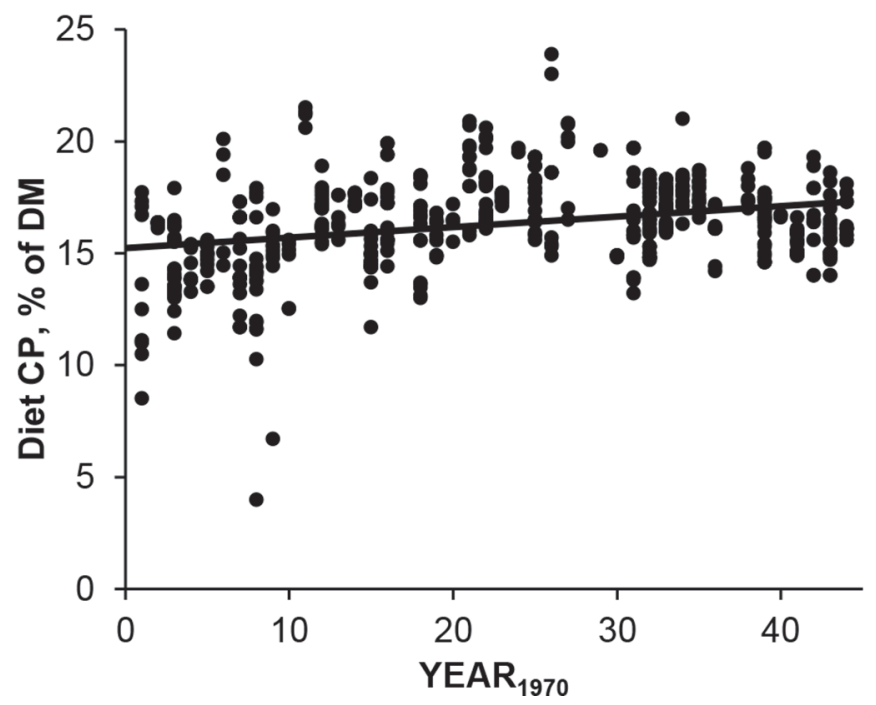

B

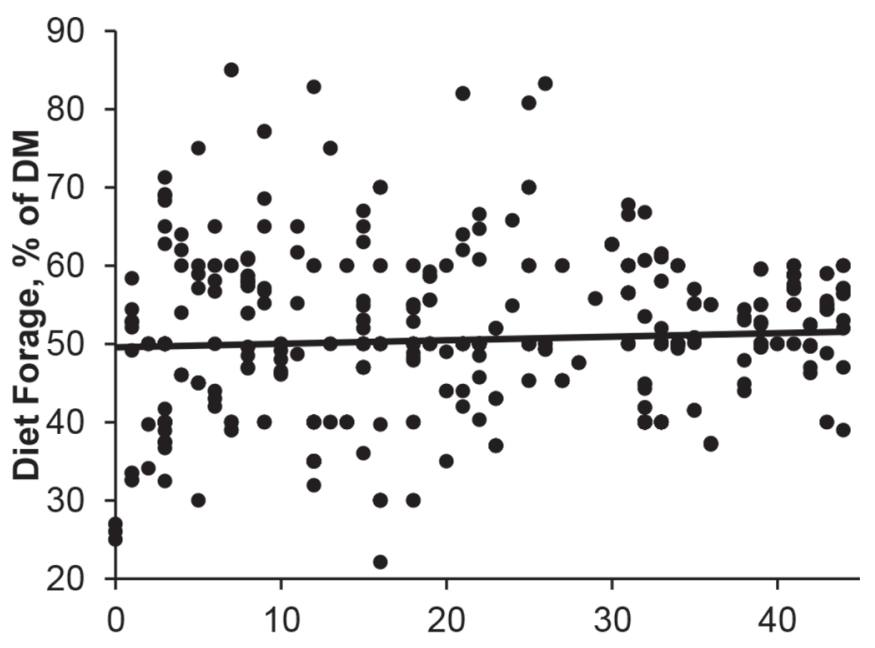

D

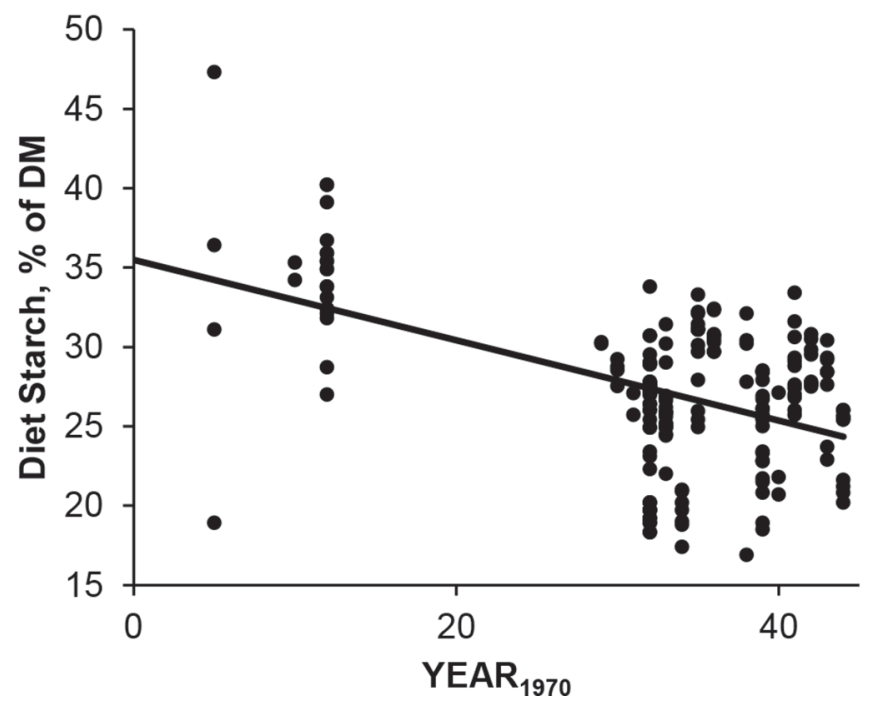

Figure 6. Relationship between publication year minus $1970\left(\mathrm{YEAR}_{1970}\right)$ and $(\mathrm{A}) \mathrm{NDF}$ content as a percentage of diet $\mathrm{DM}(\mathrm{y}=-0.12 \mathrm{x}+$ 37.6 ; intercept $\mathrm{SE}=0.68$; intercept $P<0.01$; slope $\mathrm{SE}=0.02$; slope $P<0.01 ; \mathrm{R}^{2}=0.07$; $\mathrm{RMSE}=4.61 ; \mathrm{n}=394$ ), (B) forage content as a percentage of diet $\mathrm{DM}\left(\mathrm{y}=0.04 \mathrm{x}+49.6\right.$; intercept $\mathrm{SE}=0.90$; intercept $P<0.01 ;$ slope $\mathrm{SE}=0.03 ;$ slope $P=0.18 ; \mathrm{R}^{2}<0.01 ; \mathrm{RMSE}=10.1$; $\mathrm{n}=532)$, (C) diet $\mathrm{CP}$ content as a percentage of diet DM $(\mathrm{y}=0.05 \mathrm{x}+15.3$; intercept $\mathrm{SE}=0.18$; intercept $P<0.01$; slope $\mathrm{SE}=0.007$; slope $\left.P<0.01 ; \mathrm{R}^{2}<0.09 ; \mathrm{RMSE}=1.98 ; \mathrm{n}=528\right)$, and $(\mathrm{D})$ diet starch content as a percentage of diet $\mathrm{DM}(\mathrm{y}=-0.25 \mathrm{x}+35.6 ;$ intercept $\mathrm{SE}=1.14 ;$ intercept $P<0.01$; slope $\mathrm{SE}=0.03$; slope $\left.P<0.01 ; \mathrm{R}^{2}=0.23 ; \mathrm{RMSE}=4.44 ; \mathrm{n}=195\right)$. RMSE $=$ root mean squared error.

our regression analysis, studies with a lower standard error of the mean received greater weight such that even if there was a bias in studies that used iNDF, those studies had a reduced effect compared with TC studies with respect to temporal effects on digestibility. For our summary, temporal effects on DM digestibility were no longer significant when TC and iNDF methods were analyzed separately for both Models 1 and 2 .

Many factors affect the digestive efficiency of a cow, such as diet composition, associative effects among in- dividual feeds in the diet, and rate of digesta passage through the digestive tract (Tyrrell and Moe, 1975). It is well established that increasing feed intake reduces diet digestibility when cows are fed the same diet at maintenance versus productive levels of feed intake (Tyrrell and Moe, 1975). The NRC (2001) uses a continuous discount to adjust apparent diet digestibility for level of feed intake, but the associative effect of diet ingredients is based on the digestibility of the diet when fed at maintenance. High-digestibility feeds and 
diets are assumed to exhibit a greater depression in digestibility with increasing feed intake (NRC, 2001). Therefore, it was expected that observed increases in DMI, as related to increases in both milk production and BW, would reduce digestibility.

However, some question exists about whether the decline in digestibility with increasing intake is as severe once cows reach levels of intake sufficient to support high milk production (Huhtanen et al., 2009). Our results for Model 2 indicated that intake had a significant effect on the reduction of DM digestibility between 1970 and 2014 and suggest that the observed decline in digestive efficiency was partially dependent on concurrent increases in DMI. Additional reasons for the decline in digestive efficiency could also be related to the fact that modern dairy cows prioritize nutrient demands for milk production above all other needs and consume diets that enable them to increase feed intake until these demands are met. Even a 10\% increase in digestive efficiency would be insufficient to supply enough absorbed nutrients to meet a $99 \%$ increase in milk production. Thus, the cow must compensate by consuming larger quantities of feed DM to make up the deficit. It is assumed that the size of the gastrointestinal tract directly correlates to BW (Clauss et al., 2007), and the regression-predicted BW of cows in the studies summarized increased by $19 \%$ since 1970 . This implies that the modern dairy cow likely has a larger digestive tract than the 1970s dairy cow, which would increase the cow's gut capacity. However, results reported by Clauss et al. (2007) suggest that small but diminishing gains in retention time occur as body size increases. Thus, potential advantages in digestive efficiency as related to increases in body size are likely negligible after considering the additional maintenance requirements associated with increases in gastrointestinal tissue mass. A more plausible explanation is that due to the intense genetic selection of dairy cows for milk production, cows probably have inadvertently been selected for high feed intake capacity regardless of potential losses in digestive efficiency.

Differences in the age of cows between 1970 and 2014 may have also contributed to the decrease in digestive efficiency. The average productive life of dairy cows in the United States decreased from 35.0 to 28.2 mo between 1970 and 2013 (Council for Dairy Cattle Breeding, 2016). In an earlier summary, Hare et al. (2006) suggested that this may be attributable to more intensive voluntary culling. Grandl et al. (2016) recently suggested that mature cows have an advantage in apparent total-tract digestibility of NDF over younger cows because of differences in mean particle retention time. However, only 7 of the 154 individual research studies in our data set used only primiparous cows, whereas 19 of the 154 trials used a mix of primiparous and multiparous cows. Thus, the small number of individual trials that reported the use of only primiparous cows precludes us from making any definitive conclusions regarding the influence of cow age or parity on our findings.

Because NDF digestion rate in the rumen is relatively slow, it should be very sensitive to changes in rate of passage associated with increases in feed intake. Assuming a mean diet NDF percentage of 34.2 (Table 1 ) and multiplying that by the decline in NDF digestibility $(0.342 \times-0.17=0.058$; Table 2$)$ suggests that most of the 0.07 percentage unit/yr decline in $\mathrm{DM}$ digestibility was associated with the decline in NDF digestibility. This is consistent with the observed effect of time on NDF digestibility where the coefficient for $\mathrm{YEAR}_{1970}$ decreased from -0.17 to -0.07 when $\mathrm{DMI}_{\mathrm{BW}}$ was included in the model (Model 1 vs. Model 2).

In addition to gut retention time, other factors that can influence digestive efficiency include the composition of the diet, the nature of feedstuffs, and associative effects among dietary constituents and their interactions with the microbial populations in the rumen. The forage content of the diets did not change, but diet $\mathrm{CP}$ percentage increased and diet NDF percentage decreased slightly over the 44-yr period. However, there appeared to be much larger ranges for the NDF, forage, and $\mathrm{CP}$ contents of the diets fed in studies published in the 1970s and 1980s. Decreasing the stage of forage maturity at harvest is known to decrease NDF concentration and increase NDF digestibility. With gradual improvements in forage management over time, we would have expected increased forage quality, reduced NDF concentration, and increased NDF digestibility with increasing publication date. On the contrary, our results from Model 1 indicate that NDF digestibility may have in fact decreased over the 44-yr period studied, although the temporal effect on NDF digestibility was no longer significant once feed intake was accounted for using Model 2. Furthermore, the types of forages offered in the diets do not appear to have changed over the 44-yr period (Supplemental Table S1; https://doi. org/10.3168/jds.2017-12641), with corn silage, grass and legume silage, and alfalfa hay being the predominant forage sources throughout the 44-yr period.

Dietary starch and NFC concentrations were available in only $34 \%$ and $23 \%$ of the individual trials in our data set, respectively. The diet starch content appears to have decreased between 1970 and 2014, which could have influenced DM digestibility over this period. However, because of the very limited number of studies that reported starch content of diets before the early 2000s $(\mathrm{n}=9)$, implications of this trend should be made with caution. It is worth noting that the common mode of 
ration delivery changed over the period of time we examined: Many studies in the 1970s and 1980s provided cows forage and grain separately according to level of production, whereas more recent studies provided cows with a TMR (Supplemental Table S1; https:// doi.org/10.3168/jds.2017-12641). This shift in feeding management could have influenced overall trends for mean diet composition.

Despite the simultaneous increases in DMI, advances in milk production have improved milk production efficiency (defined as FCM/DMI) primarily via the dilution of the cow's maintenance requirements (VandeHaar and St-Pierre, 2006). However, our results indicate that this improvement in milk production efficiency may have coincided with a slight reduction in the cow's digestive efficiency. In a reanalysis of USDA-Beltsville calorimetry data, Moraes et al. (2015) found no differences in ME concentration of diets fed to those cows over 3 consecutive decades. However, they did note an increase in both the maintenance requirements and the efficiency of utilization of ME for milk production in experiments conducted from 1984 to 1995. They suggested that cows producing more than $38 \mathrm{~kg}$ of ECM/d in the more recent experiments would be more efficient than cows in earlier experiments. Changes in maintenance requirements and digestive and $\mathrm{ME}$ efficiencies could have an effect on the overall biological efficiency of the dairy cow.

After accounting for differences in diet composition, DM digestibility in our summary was estimated to decrease by 3.08 percentage units from 1970 to 2014 . However, the decline in DM digestibility between 1970 and 2014 was no longer significant after concurrent changes in DMI were accounted for, suggesting that the observed decline in digestive efficiency was mostly related to increased digesta passage rate (Tyrrell and Moe, 1975). To our knowledge, no other research has been conducted to examine historical changes in digestibility in lactating dairy cows. Given recent attention to the improvement of feed efficiency in dairy cattle and other livestock species (Berry and Crowley, 2013; Connor, 2015; VandeHaar et al., 2016), our results provide information pertinent to these objectives because digestion is a major component of biological efficiency. If we assign a feed efficiency to dairy cows based on milk yield per unit of digested DM $(\mathrm{DMI} \times$ digestibility), our data suggest that the modern cow produces approximately $18.4 \%$ more milk per unit of digested DM (2.45 vs. 2.08 $\mathrm{kg}$ of milk/ $\mathrm{kg}$ of digested DM) than the cow in 1970. Although digestive efficiency appears to have decreased by approximately $2.8 \%$ between 1970 and 2014, overall production efficiency per unit of feed consumed and digested has increased. Thus, the modern dairy cow is able to achieve greater milk production per unit of digested DM by consuming significantly more feed to meet nutrient demands to compensate for small reductions in digestive efficiency.

\section{CONCLUSIONS}

Based on digestibility studies conducted at US research institutions, DM digestibility decreased by 1.9 percentage units between 1970 and 2014. After adjusting for differences in diet composition, the decline was 3.08 percentage units. However, after accounting for both diet composition and feed intake, the decline in digestibility was not statistically significant. Thus, it seems likely that the rate of passage of feed through the digestive tract accounts for a substantial portion of the observed decline in digestive efficiency between 1970 and 2014. Other causes for the reduction in digestive efficiency are unclear but could also be related to a combination of other changes associated with intense selection for milk production over this period. Despite the decline in apparent total-tract digestibility of DM between 1970 and 2014, the modern dairy cow still achieves greater levels of production per unit of DM consumed and digested.

\section{REFERENCES}

Adams, M. W., R. L. Belyea, and F. A. Martz. 1988. Effects of variety and particle size upon utilization of fescue hay by lactating dairy cows and dairy heifers. J. Dairy Sci. 71:1275-1282.

Beavers, L., and B. Van Doormaal. 2016. A closer look at stature. Accessed Nov. 15, 2016. https://www.cdn.ca/document.php?id=441.

Belyea, R. L., F. A. Martz, and G. A. Mbagaya. 1989. Effect of particle size of alfalfa hay on intake, digestibility, milk yield, and ruminal cell wall of dairy cattle. J. Dairy Sci. 72:958-963.

Bermingham, M. L., D. P. Berry, and A. R. Cromie. 2006. Irish Holstein-Friesian cows are taller now than a decade ago. Accessed Nov. 15, 2016. http://www.agresearch.teagasc.ie/moorepark/ Publications/pdfs/Research\%20Report\%202006.pdf.

Berry, D. P., and J. J. Crowley. 2013. Cell biology symposium: Genetics of feed efficiency in dairy and beef cattle. J. Anim. Sci. 91:1594-1613.

Clauss, M., A. Schwarm, S. Ortmann, W. J. Streich, and J. Hummel. 2007. A case of non-scaling in mammalian physiology? Body size, digestive capacity, food intake, and ingesta passage in mammalian herbivores. Comp. Biochem. Physiol. Part A. Mol. Integr. Physiol. 148:249-265.

Cochran, R. C., D. C. Adams, J. D. Wallace, and M. L. Galyean. 1986. Predicting digestibility of different diets with internal markers: Evaluation of four potential markers. J. Anim. Sci. 63:1476-1483.

Colucci, P. E., L. E. Chase, and P. J. Van Soest. 1982. Feed intake, apparent diet digestibility, and rate of particulate passage in dairy cattle. J. Dairy Sci. 65:1445-1456.

Connor, E. E. 2015. Invited review: Improving feed efficiency in dairy production: Challenges and possibilities. Animal 9:395-408.

Connor, E. E., J. L. Hutchison, H. D. Norman, K. M. Olson, C. P. Van Tassell, J. M. Leith, and V. R. L. Baldwin. 2013. Use of residual feed intake in Holsteins during early lactation shows potential to improve feed efficiency through genetic selection. J. Anim. Sci. 91:3978-3988.

Council for Dairy Cattle Breeding. 2016. Trend in productive life for Holstein or Red and White. Accessed Nov. 16, 2016. https://www. cdcb.us/eval/summary/trend.cfm?R_Menu=HO.l\#StartBody. 
Dado, R. G., and M. S. Allen. 1996. Enhanced intake and production of cows offered ensiled alfalfa with higher neutral detergent fiber digestibility. J. Dairy Sci. 79:418-428.

Firkins, J. L., M. S. Allen, B. S. Oldick, and N. R. St-Pierre. 1998 Modeling ruminal digestibility of carbohydrates and microbial protein flow to the duodenum. J. Dairy Sci. 81:3350-3369.

Grandl, F., S. P. Luzi, M. Furger, O. Zeitz, F. Leiber, S. Ortmann, M Clauss, and M. Kreuzer. 2016. Biological implications of longevity in dairy cows: 1 . Changes in feed intake, feeding behavior, and digestion with age. J. Dairy Sci. 99:3457-3471.

Hansen, L. B. 2000. Consequences of selection for milk yield from a geneticist's viewpoint. J. Dairy Sci. 83:1145-1150.

Hare, E., H. D. Norman, and J. R. Wright. 2006. Survival rates and productive herd life of dairy cattle in the United States. J. Dairy Sci. 89:3713-3720.

Huhtanen, P., K. Kaustell, and S. Jaakkola. 1994. The use of interna markers to predict total digestibility and duodenal flow of nutrients in cattle given six different diets. Anim. Feed Sci. Technol. 48:211-227.

Huhtanen, P., M. Rinne, and J. Nousiainen. 2009. A meta-analysis of feed digestion in dairy cows. 2. The effects of feeding level and diet composition on digestibility. J. Dairy Sci. 92:5031-5042.

Lee, C., and A. N. Hristov. 2013. Short communication: Evaluation of acid-insoluble ash and indigestible neutral detergent fiber as total-tract digestibility markers in dairy cows fed corn silage-based diets. J. Dairy Sci. 96:5295-5299.

Lippke, H., W. C. Ellis, and B. F. Jacobs. 1986. Recovery of indigestible fiber from feces of sheep and cattle on forage diets. J. Dairy Sci. 69:403-412.
Macdonald, K. A., J. E. Pryce, R. J. Spelman, S. R. Davis, W. J. Wales, G. C. Waghorn, Y. J. Williams, L. C. Marett, and B. J. Hayes. 2014. Holstein-Friesian calves selected for divergence in residual feed intake during growth exhibited significant but reduced residual feed intake divergence in their first lactation. J. Dairy Sci. 97:1427-1435.

Moraes, L. E., E. Kebreab, A. B. Strathe, J. Dijkstra, J. France, D. P. Casper, and J. G. Fadel. 2015. Multivariate and univariate analysis of energy balance data from lactating dairy cows. J. Dairy Sci. 98:4012-4029

National Agricultural Statistics Service (NASS). 2016. Quick stats Accessed Nov. 16, 2016. https://quickstats.nass.usda.gov/ results/99223A11-A246-341D-9238-72B6FD0E25E9.

NRC. 2001. Nutrient Requirements of Dairy Cattle. 7th ed. Natl Acad. Press, Washington, DC.

St-Pierre, N. R. 2001. Invited review: Integrating quantitative findings from multiple studies using mixed model methodology. J. Dairy Sci. 84:741-755.

Tyrrell, H. F., and P. W. Moe. 1975. Effect of intake on digestive efficiency. J. Dairy Sci. 58:1151-1163.

VandeHaar, M. J., L. Armentano, K. Weigel, D. Spurlock, R. Tempelman, and R. Veerkamp. 2016. Harnessing the genetics of the modern dairy cow to continue improvements in feed efficiency. J. Dairy Sci. 99:4941-4954.

VandeHaar, M. J., and N. St-Pierre. 2006. Major advances in nutrition: Relevance to the sustainability of the dairy industry. J. Dairy Sci. 89:1280-1291. 